الكثف عن تواجد الفطريات في بعض الأغذية المنتجة محليا والمستوردة (دراسة

خولة عبد السلام القمودي 1، مروى عبد الوهاب الثرشاري²، مودة الكوني البكوش³

نهى البثير كاكا4، سارة عبد الرحمن هويسه5 أسماء النفاتي الجهاني6، ابتسام عمر عامر 7 7.564،3،2،11 ميكروبيولوجيا الأغذية-كلية التقنية الطبية صرمان، جامعة صبراته

6 علم الفطريات-كلية التربية جامعة طرابلس

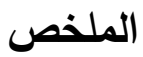

تعد البقوليات بديلاً عن اللحوم لاحتوائها على نسبة عالية من البروتينات، وتدخل في العديد من وصفات الطعام. ويعتبر سوء التخزين من العوامل التي تؤدي إلى زيادة نمو الميكروبات والجراثيم خاصّة الفطريات التي تعمل على إفراز السموم بالأطعمة مما يؤدي إلى إتلافها. الكثف عن تواجد الفطريات في الأغذية المنتجة محلياً والمستوردة وشملت كلا من التوابل كالفلفل وبذور الحص وثمار التمر المعروضة للبيع بالأسواق.

جمعت العينات الغذائية بمنطقه الدراسة لكل من الصنف المحلي والمستورد، في أوعية معقدة لعدد ثلاث عينات من كل نوع تضمنت ( بذور الحمص والفلفل الأحمر والتمر ) بمعل وزني مقدار 500 غرام لكل عينة.

ووضعت في كل من بيئة الآجار المغذية وماء البيتون لمدة 6 ساعات ومنها زرعت العينات على أوساط إنمائية وتثخيصية Sabouraud Dextrose Agar Potato dextrose agar لنمو الميكروبات (فطور وخمائر) وحضنت في 250 درجة مئوية لمدة 5 أيام، بعد الحصول على المزارع النقية حضرت العينة الفطرية للفحص المجهري للفطور .

أظهرت نتائج العزل وجود خمسة أنواع من الفطريات بالعينات المدروسة حيث تبين أنّ كافة عينات بذور الحمص ملوثة بينما لوحظ أنّ عينات الفلفل الأحمر المستورد ملوثة أكثر من الفلفل المحلي. كما بال 
لوحظ عدم تلوث عينة واحدة من أصل عدد ثلاث عينات لثمار التمر ـ هذا وشملت الفحوص المجرية

للعزل الفطريات التالية: Alternaria alternata، Aspergillus flavus ،spp و . Aspergillus niger وتشير النتائج إلى أن المواد الغذائية . تتعرض للتلوث نتيجة لعدم إتباع الطرق الصحيحة في التخزين والعرض بالأسواق.

يجب على مراكز التظّية الاهتمام بالمواد الغذائية المستوردة بأن تخضع لشروط الصحة العامة بالجودة

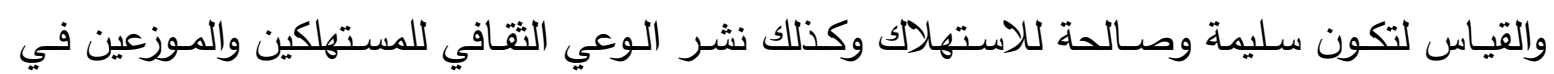
الحفاظ على الصحة الغذائية والتوصية أيضا باستكمال الدراسة بإجراء مسح شامل لعدد عينات أكثر والتعرف على سمية الفطريات المعزولة

Potato الكلمـات المفتاحية: المواد الغذائية، الفطريات، بذور الحمص، الفلفل الأحمر، التمر .dextrose agar

المقدمة

يقصد بالتلوث الغذائي أو تلوث الأغذية وصول الكائنات الحية الدقيقة كالبكتيريـا والفطريات أو أي أجسام غريبة غير مرغوب بوجودها في المـادة الغذائية(1).حيث تتمو بعض أنواع الفطريـات على الأغذية وتفرز سموماً تعرف السموم الفطريـة Mycotoxins تكون شديدة الخطورة على صحة الإنسان و تسبب سرطان الكبد وخلاً بوظائف القلب والأنسجة المختلفة ، وكذلك حدوث تغيرات وراثية

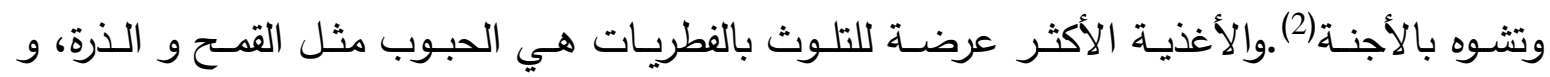
البقوليات مثل : الحمص إلى جانب الأنواع المختلفة من المكسرات مثل البندق ، اللوز والفواكه الدجفة مثل : التين ، المشمش ، الزبيب والبلح. تصبح الأغذية سامة نتيجة لتلوثها بالسموم عند استخدام عبوات ومواد تغليف غير مناسبة أو بتلوثها من المعدات الملامسة لها أثناء عمليات التصنيع. مها يعجل في ظهور علامـات الفساد عليها وبالتالي جعلها غير مرغوبـة أو غير صـالحة للاستهلاك البشري. وقد اهتم الباحثون بدراسة وتحليل الملوثات الغذائية وتحديد كمياتها والأضرار الناجمة عنها

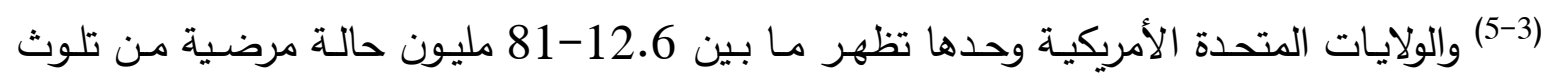
الغذاء سنوياً، وتسبب البكتربا حوالي 87 \% من مثل هذه الحالات، ومثل هذه الأمراض تسبب خسارة فادحة ليس للشخص المريض فقط بل تمتد لصناعة الغذاء والاقتصاد القومي، وتقدر الخسارة حوالي 
4.8-7.7 بليـون دولار سـنوياً (6-9). مدـا أدى إلـى زيـادة الـوعي لـدى المختصـين في الملوثـات وأضرارها، وأنشئت هيئات تقوم بمراقبة سلامة الأغذية من الملوثات وسن القوانين التي تتظم ذلك (9) . أهداف البحث عزل وتعريف الفطريات في بعض المواد الغذائية المحلية والمستوردة والتتي تضمنت كلاً من (بذور الحمص، والتوابل الفلفل الأحم، والتمر المجفف).

التقدير الكمي لهذه الفطريات ومقارنتها بالمواصفة القياسية العربية الموحدة رقم 1486 لسنة .2002

المواد وطرائق البحث

جمع العينات

العينات المستهدفة في هذه الدراسة شملت ثلاث عينات من المواد الغذائية محلية ومستوردة (الحمص والفلفل والتمر ) جمعت بشكل عشوائي من محلات البيع بواقع ثلاث عينات لكل نوع من ثلاث مناطق مختلفة (منطقة الوادي بمدينة صبراته ومنطقتين الثاطي والعين بمدينة صرمان) بعبوات معقدة كبيرة بسعة 500 جرام مـع تكرار العينة ثـلاث مرات ومكتوب عليها بطاقة تعريف تتضمن رقم وتاريخ ومنطقة جمع العينة، وتم نقل العينات خلال 6 ساعات إلى المعمل وحدة الأحياء الدقيقة بقم التقنية الحيوية بالكلية.

عزل وتعريف الفطريات المحمولة ببذور الحمص

تم عزل الفطريات من البذور باستخدام طريقة ورق الترشيح Blotter MethodB(10) ، وذلك بغر 50 بذرة من الحمص في كأس يحتوي على محلول هيبوكلوريت الصوديوم (NaOCl) تركيزه 5\% لمدة

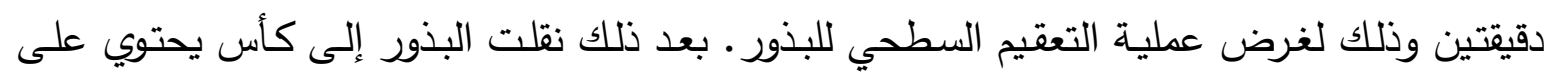

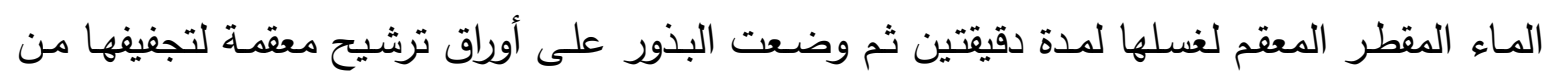
الماء الزائد.

تم توزيـع البذور على أطباق بتري تحتوي على 3 أوراق ترشيح معقدة مبللة بالماء المقطر المعقم، حيث وضعت 10 بذور حصص طبق بواقع 9 بذور في محيط الطبق وبذرة واحدة بالمنتصف. وتركت 
الأطباق عند درجة حرارة الغرفة (24 م 3 (2) لمدة 5-7 أيام تحت إضـاءة متبادلة 12 ساعة إضـاءة و12 ساعة ظلام. بعد ظهور النموات الفطرية على البذور تم نقل جزء من هذه النموات إلى أطباق

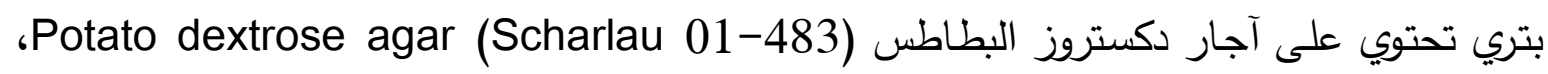
وذلك للحصول على مزارع نقية من الفطريات بواقع 3 مكررات لكل فطر ـ. وتم حساب النسبة المئويـة للبذور المصابة باستعمال المعادلة التالية:

$$
\text { النسبة المئوية للبذور المصابة = }=100 \text { ×دد الذور المصابة بالفطر اللبذر }
$$

حضرت شرائح للفحص المجهري وذلك بنقل جزء من النمو الفطري ووضعاه على شريحة تحتوي على

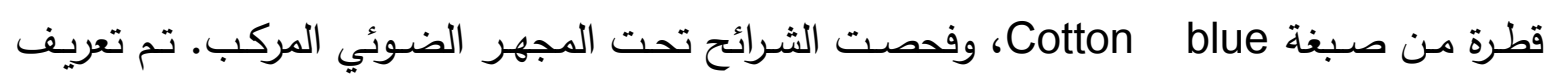
الفطريات بناء على صفات المستعمرة من حيث الثكل، اللون والسمات الظاهرية للوحدات التكاثرية (الأنواع) وذلك باستخدام مفاتيح التعريف المناسبة (11). عزل وتقدير الفطريات من الفلفل الأحمر والتمر تم وزن 10 جرام من كل عينة من الفلفل والتمر وإضافتها كل على حدى إلى أنبوبة تحتوي على 90 مل من الحساء المغذي Sabouraud dextrose broth و حضنت لمدة ساعة عند 25 مْ بعد ذلك تم إجراء 5 تخفيفات لكل عينة، وذلك بنقل 1 مل من المحلول المحتوي على العينة والحساء المغذي إلى أنبوبة اختبار تحتوي على 9 مل من ماء الببتون Peptone water؛ وكانت التخفيفات

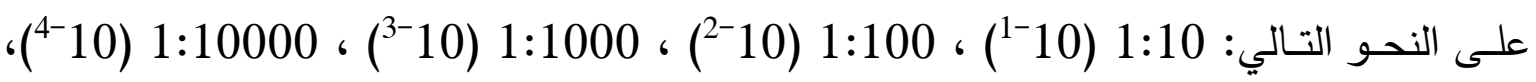

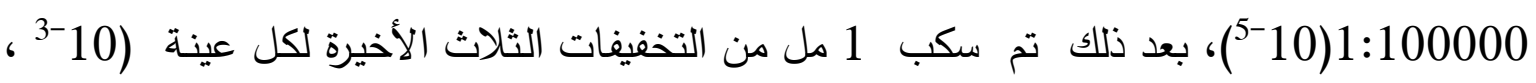
10 45-50 مْ و حركت الأطباق حركة دائريـة بعكس واتجاه عقارب السـاعة وبواقع 3 مكررات لكل •تركيز تركت الأطباق في درجة حرارة الغرفة (24 مث 3) لمدة 5 أيام ، بعدها تم عد الفطريات الموجودة في كل تركيز، حضرت شرائح من النموات الفطرية لفحصها تحت الميكروسكوب وتم تعريف الفطريات 
بنـاء على صفات المستعمرة من حيث الثكل واللون والسمات الظاهريـة للوحدات التكاثريـة، وذلك باستخدام مفاتيح التعريف المناسبة(2).

\section{النتائج والمناقشة}

$$
\text { بينت النتائج أن الفطريات التي تم عزلها من العينات قيد الدراسة هي: }
$$

Alternaria ، Fusarium oxysporum ، Aspergillus niger، Aspergillus flavus

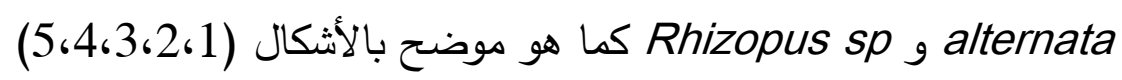

أولا فيما يتعلق ببذور الحمص: فقد تم عزل كل الفطريات المذكورة سابقا من بذور الحمص، حيث كانت أعلى نسبة إصـابة بهذه الفطريات كانت في منطقة العين كما هو موضـح بالجدول رقم (1)، والثكل (6) يوضح العدد اللوغاريتمي للفطريات بالعينات الغذائية المدروسة.

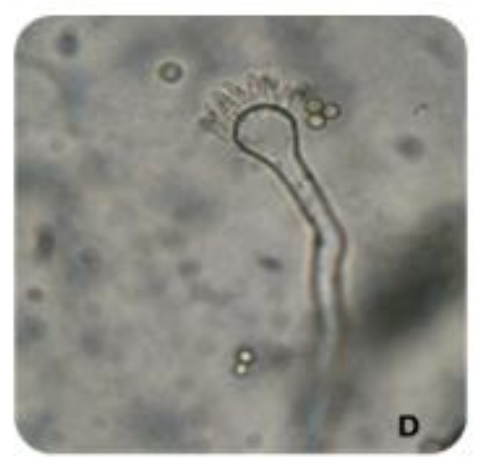

الحوامل الكوثينية والجز اثيم الكوبيدية

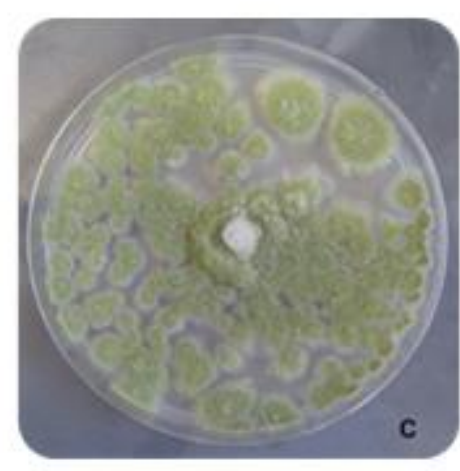

PDA مسنعمرة نتبة للفطز ملى بيئة

شكل (1): Aspergillus flavus.

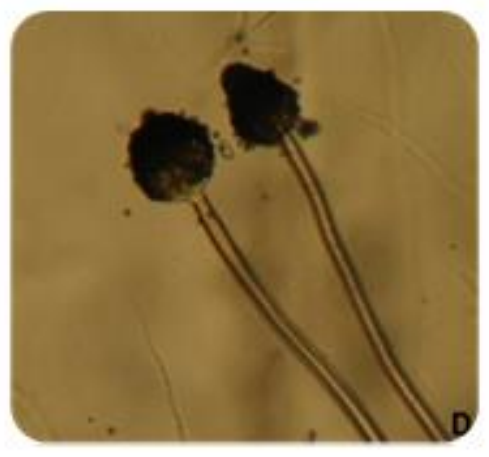

الحوامل الكوتيدية الأبواغ الكوبيدية.

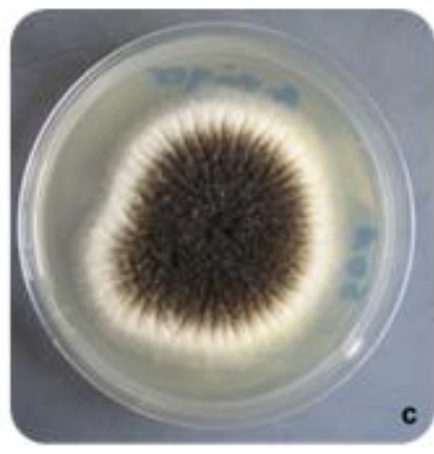

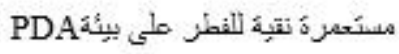

شكل (2): Aspergillus niger. 


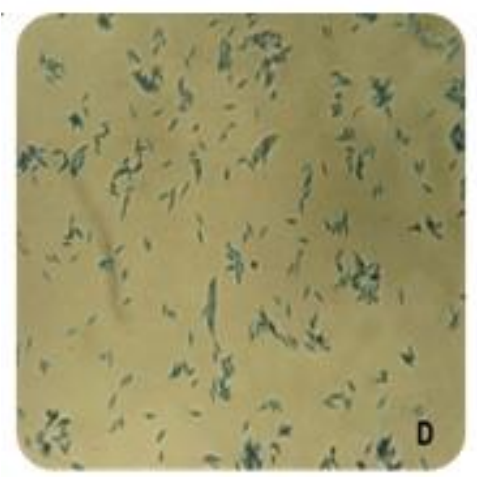

الجز انتيم الكوتبدية الكبيردُ و الصنيرة.

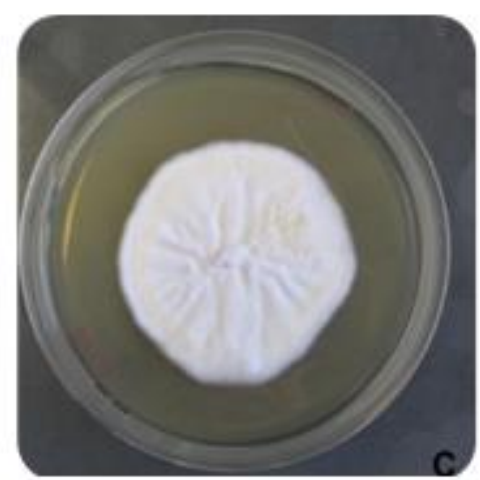

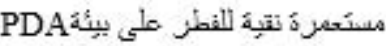

شكل (3): Fusarium oxysporum.

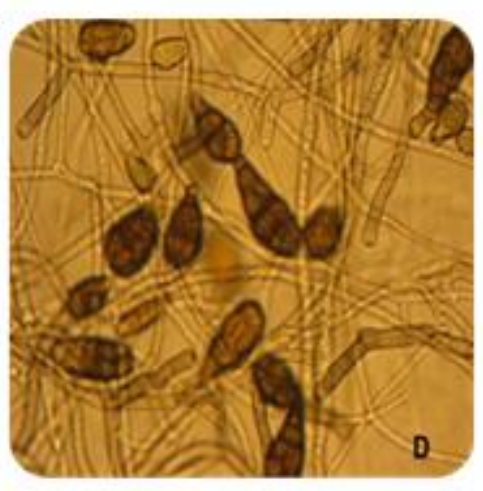

الحوامل الكونيدية الأبيواغ الكونبدية.

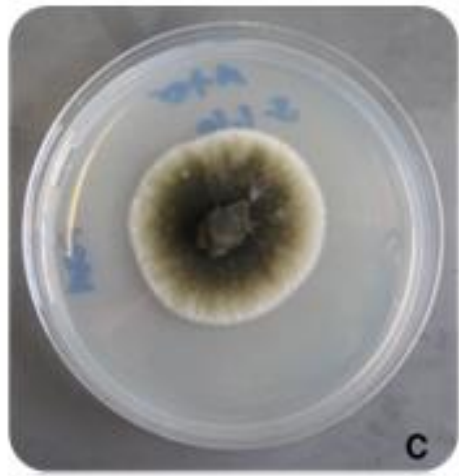

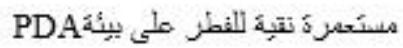

شكل (4):Alternaria alternata.

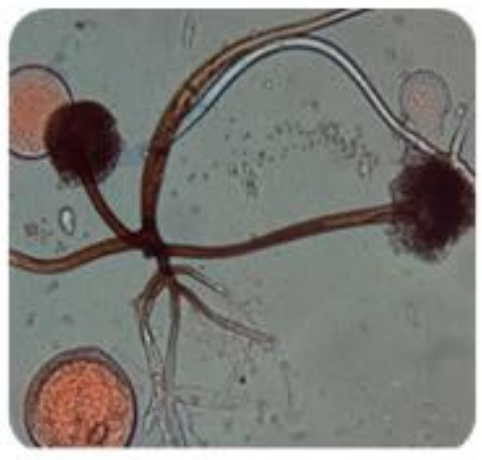

الحوامل الكونبدية الأبيواغ الكونينية.

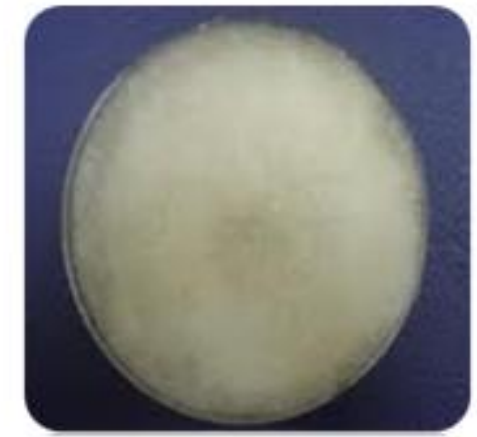

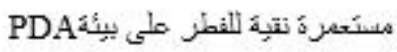

شكل (5): Rhizopus spp . 
الجدول (1): يوضح النسبة المئوية لبذور الحمص المصابة بالفطريات.

\begin{tabular}{|c|c|c|c|c|c|}
\hline \multicolumn{5}{|c|}{ النسبة المئوية للبذور المصابة } & الفظر \\
\hline Rhizopus sp & F. oxysporum & A. alternata & A. niger & A. flavus & المنطقة \\
\hline- & 14 & 16 & 30 & 40 & الثاطي \\
\hline 7 & - & 12 & 38 & 50 & الوادي - لمي \\
\hline 10 & 18 & 24 & 60 & 42 & 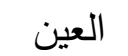 \\
\hline
\end{tabular}

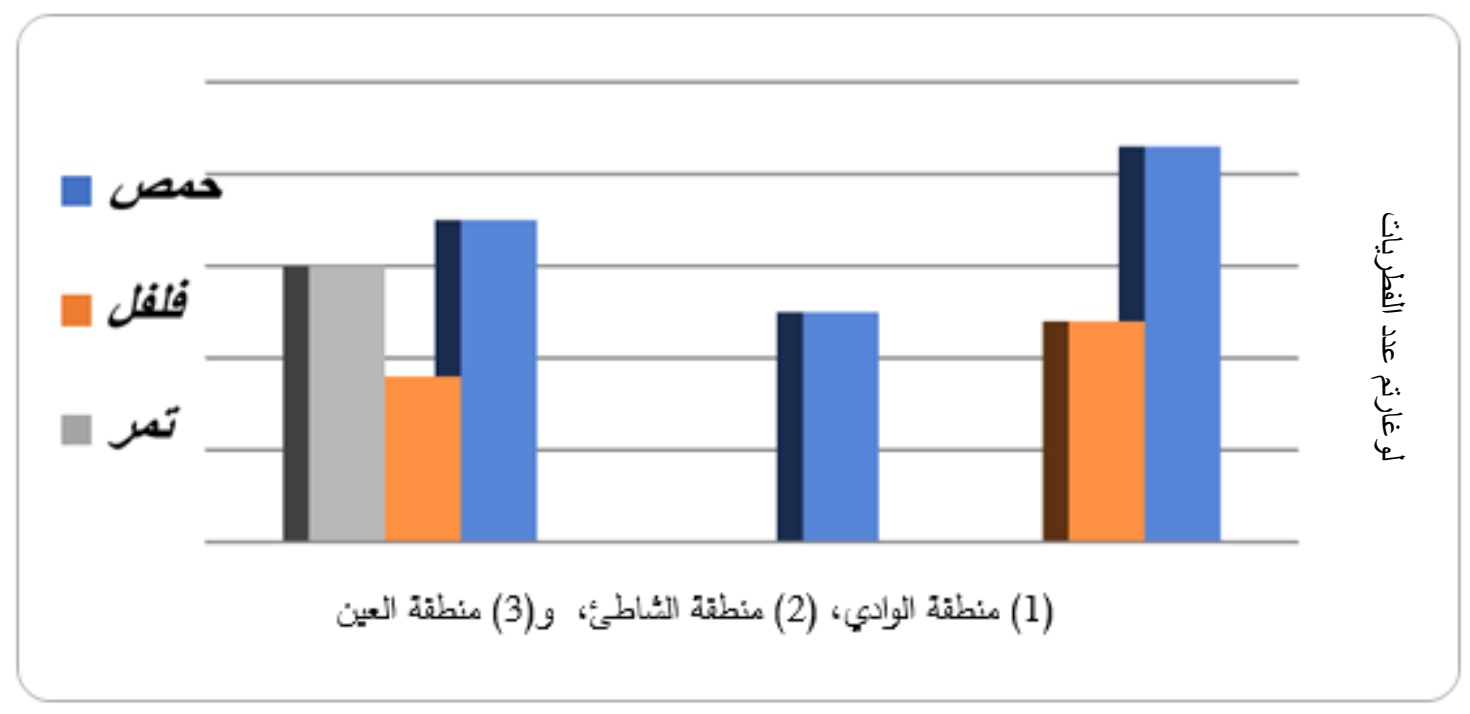

شكل (6): يوضح العدد اللوغاريتمي للفطريات بالعينات الغذائية المدروسة.

ثانيا: فيما يتعلق بالفلفل الأحمر المحلي (التوابل) فلقد أظهرت النتائج عدم وجود تلوث بالعينات التي تم تجميعها من منطقة الثـاطي ، بينما كان الفلفل الأحمر المستورد المأخوذ من منطقتي الوادي

والعين ملوثا بالفطريات التالية A. niger، Rhizopus spp، كما هو موضح بالجدول رقم (2)alternata ثالثا: بالنسبة لعينات التمر (ثمار مجففة)، فلقد وجد أن العينات المأخوذة من منطقتي الثاطي والوادي كانت غير ملوثـة بالفطريـات، في حين أن عينـات التمر المجمعـة مـن منطقـة العين كانت ملوثـة بفريات F. oxysporum و A. alternata حسب ما هو موضح بالجدول رقم (2). 
جدول (2): يوضح عدد الفطريات في الفلفل الأحمر والتمر.

\begin{tabular}{|c|c|c|c|c|c|c|}
\hline \multicolumn{5}{|c|}{ عدد الفطريات (عدد المستعمرات / مل) } & \multirow{2}{*}{ الفينة } & \multirow[b]{2}{*}{ ل المنطقة } \\
\hline $\begin{array}{c}\text { A. } \\
\text { alternata }\end{array}$ & $\begin{array}{c}F . \\
\text { oxysporum }\end{array}$ & $\begin{array}{c}\text { Rhizopus } \\
\text { sp }\end{array}$ & A. niger & $\begin{array}{c}A . \\
\text { flavus }\end{array}$ & & \\
\hline \multicolumn{5}{|c|}{ لا لا يوجد نمو } & (الفلفل الأحمر & \multirow[t]{2}{*}{ 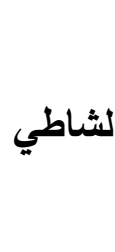 } \\
\hline \multicolumn{5}{|c|}{ ل الا يوجد نمو } & التمر & \\
\hline & $4 \times 10^{4}$ & $3 \times 10^{4}$ & $6 \times 10^{5}$ & - & الفلفل الأحمر & \multirow[t]{2}{*}{ 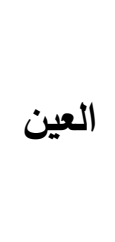 } \\
\hline $5 \times 10^{5}$ & $11 \times 10^{4}$ & - & - & - & 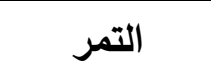 & \\
\hline & $3 \times 10^{5}$ & $2 \times 10^{4}$ & $7 \times 10^{4}$ & $10 \times 10^{3}$ & الفلفل الأحمر & \multirow[t]{2}{*}{ 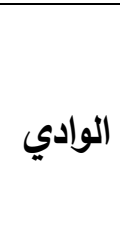 } \\
\hline \multicolumn{5}{|c|}{ ل لا يوجد نمو } & 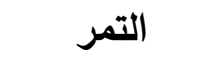 & \\
\hline
\end{tabular}

تدل النتائج أن المواد الغذائية تتعرض للتلوث بالفطريات نتيجة لعدم اتباع الأساليب الصحيحة بدء من تحضيرها وانتهاء بتخزينها وعرضها في الأسواق المحلية والثعبية.

تعد هذه النتائج أكثر من الحدود الطبيعية المسموح في المواصفات والمعايير القياسية العربية الموحدة رقم 1486 لسنة 2002، وهذا يتقق مع دراسة سابقة (13).

\section{الخلاصة}

تعد سلامة الغذاء Food Safety الهدف الرئيس لصحة الإنسان في كل دول العالم ونوصي بالآتي: تطبيق معايير الجودة للمنتجات الغذائية من المنشأ إلى المستهلك العناية بآليات حماية المستهلك.

المراقبة والتقتيش على الأغذية المستوردة خاصة الحبوب ومنتجاتها للتأكد من سلامتها وخلوها من الفطريات وسمومها. 
التحكم في ظروف التخزين مـن درجـة حرارة والرطوبـة النسبية وذلك لمنع نمو الفطريـات

$$
\text { وبالتالي إيقاف تكوين السم. }
$$

حفظ المواد الغذائية في مبردات للنع نمو الفطريات مع ضرورة تنظيف وتجفيف المبردات من

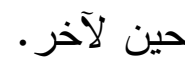

الاهتمـام بالدراسـات والبحوث المتعلقة بالفطريـات وسمومها واستكمال الدراسـة بـإجراء مسـح

$$
\text { شامل لعدد عينات أكثر والتعرف على سمية الفطريات المعزولة }
$$

علي عبد علي الراوي. 2009. عزل وتشخيص الفطريات المصاحبة لبذور بعض المكسرات

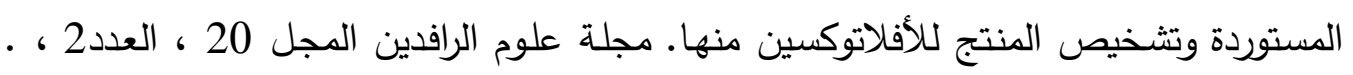

$.57-46$

• ميخائيل، سمير • ( 2000). أمراض البذور . الطبعة الثالثة. منشأة المعارف. الإسكندرية. ص

\section{2- المراجع الأجنبية:}

- Archer, D. L. and J. E. Kvenberg (1985), Incidence and cost of food bornediarrheal disease in the United States, J. Food Prot. 48:887-894.

- Bryan, F.L.H.W. Anderson, O.D. Cook, J. Guzewich, K.H. Lewis, R.C. Swanson, and E. C. D. Todd (1987). Procedures to Investigate Food borne Illness, 14th ed. International Association of milk, food and environmental sanitarians, Inc., Ames, IA. 88p.

- Bean, N. H. and P. M. Griffin (1990), Foodborne disease outbreaks in the United States, 1973-1987: Pathogens, vehicles and trends, J. Food Prot. 53:804

- Barnett,H.L. and B.Hunter. 1972. Illustrated genera of Imperfect fungi. Burgess Publishing Company. 421 pp.

- FAO/WHO. (1984). Joint FAO/WHO Food Standers Program, Codex Alimentarius Commissio Contamination. 
- Gilbert,j .(1984). Analysis of food contamination. Elsevier App.Sci. Pups., London.

- Kvenberg, J. E. and D, L. Archer (1987), Economic impact of colonization control of food borne disease, Food Technol. 41(7): 77-80.

- Todd, E. C. D. (1989), Preliminary estimates of costs of food borne disease in the United States, J. Food Prot. 52: 595-601.

- Zakrzewski, S .F (.1991). Principle of environ mental toxicology.ACS rofessional reference book, Washington ,DC,1. 